\title{
The energy efficiency of the process of metal cutting at the expense of the sustainability of the evolutionary trajectory of the cutting
}

\author{
Vilor L. Zakovorotny ${ }^{1}$, Viktor P. Lapshin ${ }^{1,}{ }^{*}$, Valery E. Gvindjiliya ${ }^{1}$, and Nguyen Dong Ahn $^{2}$ \\ ${ }^{1}$ Don State Technical University, 344000 Rostov-on-Don Gagarin square 1, Russia \\ ${ }^{2}$ Department “Aerospace technology and equipment”, Le Quy Don Technical University, Hanoi, \\ Vietnam
}

\begin{abstract}
The problem of ensuring the sustainability of the processing process is directly related to the energy efficiency of the entire processing process. Virtually any machine the control of motion of which is considered interacts with the environment (technological, aerodynamic, trybologic, etc.). If one sticks to the synergetic analytical concept, the influence of the environment is described by a model of forces in state coordinates. The interaction is also characterized by the irreversible transformation capacity trajectory on the work. As a result, the system parameters are change causing additional strain displacements changing the trajectory. This transformation characterizes internal control and they are defined not by external action but by internal self-organization and defines the evolutionary trajectory. The properties of the system along the evolutionary trajectory change and the trajectory can lose its stability. The article considers the process of mathematical simulation of the evolutionary trajectory forming by the example of metalwork by cutting at turning machines and analyzes its stability. The evolution is presented as the parameters of the system depending on the capacity and work trajectory and presented by the Volterra integral equation of the second kind. When the trajectory loses its stability, irreversible changes can be formed in the system which may cause a complete system breakdown. In addition, the loss of stability leads to an increase in the oscillation amplitude of the tool and, as a consequence, an increase in energy costs for processing.
\end{abstract}

\section{Statement of the research problem}

For the last two decades a new paradigm of analysis and synthesis of systems interacting with various environments [1-3] was formed. Their properties are related to the cutting process $[6,7]$. Energy irreversible transformations in a cutting area change the laws of interaction of the tool subsystems and the part by means of a cutting process. Irreversible energy transformations in the cutting area change the laws of the tool subsystems and parts through the treatment process. When studying the interaction laws, the scientists usually

\footnotetext{
*Corresponding author: lapshin1917@yandex.ru
} 
analyze mechanical subsystems and, consequently, the dynamics of cutting as an entirely mechanical system.

The models of subsystems on the tool and workpiece side are commonly considered in the form of finite-dimensional spatial structures. The representation of cutting forces in state coordinates are non-linear in principle and takes into account their dependence on the area of the cutting layer [8-22], regenerative self-excitation for linear [8] and non-linear [21-26] models. The delay of forces action in relation to elastic deformations [9, 13, 16, 27] is also considered as well as the decrease of forces at increased cutting speed $[12,13]$, the impact of friction forces at the tool edges [28, 29]. A significant attention was paid to stability problems. The authors also consider parametric self-excitation for the system the parameters of which are periodic time functions. There are also papers analyzing a dynamic modification of system properties in the course of functioning [30-32]. The present article develops the mentioned research for the case when the system parameters are changed due to the energy emitted in the conjunction the system - environment. In the paper the key focus is placed onto the problems of the evolutionary trajectory stability

\section{Modeling of evolutionary change}

Consider spatial elastic strain displacements $X=\left\{X_{1}, X_{2}, X_{3}\right\}^{T}$ which make the system motion trajectory deviate. We will analyze them in a lowered coordinate system. The dynamic equation is presented in the form (Fig.1)

$$
m \frac{d^{2} X}{d t^{2}}+h \frac{d X}{d t}+c X=F_{\Sigma}\left(X, V_{i, 0}, p_{s}\right), i=1,2,3 ; s=1,2, \ldots k
$$

where $\quad m=\left[m_{s, k}\right], m_{s, k}=m$, where: $s=k, m_{s, k}=0$, where: $s \neq k$ in $\quad \mathrm{kgsek}^{2} / \mathrm{mm}$, $h=\left[h_{s, k}\right]$ in $\mathrm{kgsek} / \mathrm{mm}, c=\left\lfloor c_{s, k}\right\rfloor$ in $\mathrm{kg} / \mathrm{mm}, \mathrm{s}, k=1,2,3$ - symmetrical, positively defined matrices;

$$
F_{\Sigma}=\left\{F_{\Sigma, 1}\left(X, V_{1,0}, V_{2,0}, V_{3,0}, p_{i}\right), F_{\Sigma, 2}\left(X, V_{1,0}, V_{2,0}, V_{3,0}, p_{i}\right), F_{\Sigma, 1}\left(X, V_{1,0}, V_{2,0}, V_{3,0}, p_{i}\right)\right\}-
$$

mathematical model of the dynamic connection formed by a cutting process.

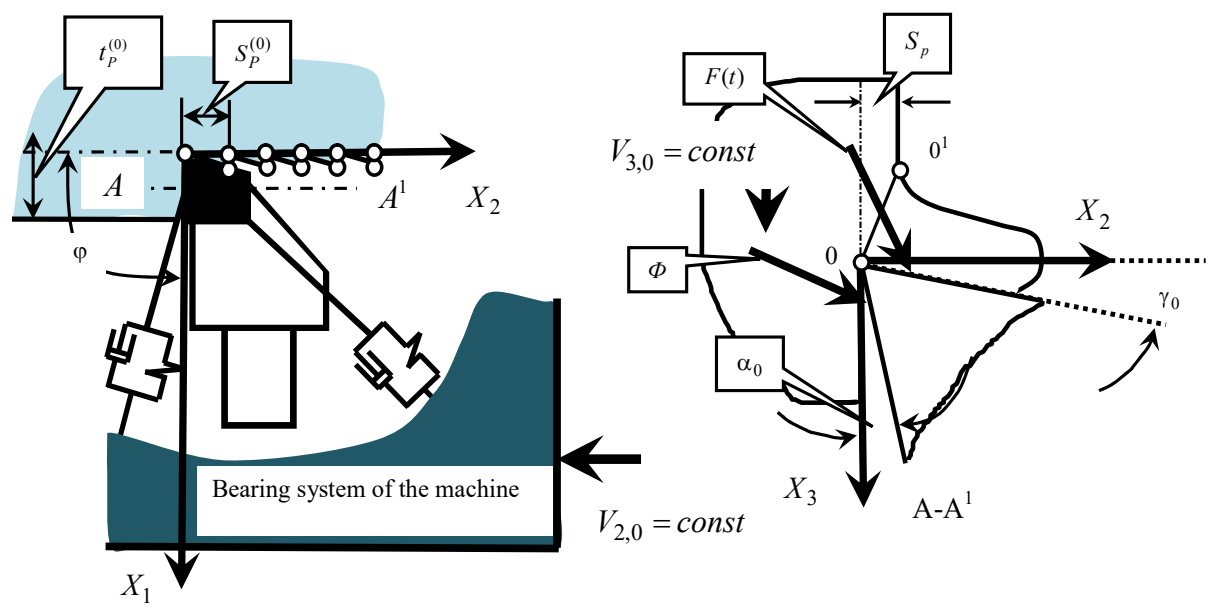

Fig.1. The pattern of the tool - workpiece interaction at cutting. 
(1) comprises the parameters $p_{i}, i=1,2, \ldots k$ which are considered to be changeable in the course of evolution. In case the speed $\phi_{i}(t)$ of changing the parameter $p_{i}$ is set then

$$
p_{i}=p_{i, 0}+\int_{0}^{t} \varphi_{i}(\xi) d \xi, i=1,2, \ldots k
$$

where $p_{i, 0}$-initial parameters at the moment $t=0$. For the simulation of $\phi_{i}(t)$ accept a basic hypothesis on the dependence of $\phi_{i}(t)$ on the capacity and work trajectory. In this case $\phi_{i}(t)$ can be presented in the form of the following Volterra equation of the second kind [33]

$$
\phi_{i}(t)=c_{\phi}\left\{N(t)+c_{\phi}^{*} \int_{0}^{t} W(t-\varsigma) N(\varsigma) d \varsigma\right\},
$$

where $c_{\phi}^{*}$ - ratio in $\left[c^{-1}\right]$, the dimensions of $c_{\phi}$ depend on the parameter; $W(t-\varsigma)$ - a nondimensional core is represented in the form of $W(t-\varsigma)=\exp \left[-\left(T_{\phi}\right)^{-1}(t-\varsigma)\right] ; T_{\phi}-$ time constant defining the hereditarity of the capacity impact in $[c]$. The parameter change as well as wear are irreversible and their rate depends not only on the current capacity value but also on its pre-history. The changes $p_{i}$ are functionally connected. For analyzing the dynamics it is necessary to present the forces $F_{\Sigma}$ in state coordinates, external impacts and industrial modes $[5,6]$. When simulating the forces, take into account their known properties: the forces $F=\left\{F_{1}, F_{2}, F_{1}\right\}^{T}$ acting on a front tool surface depend on the area of the cut layer; their change delays in relation to the variation of its surface; they decrease at the increasing of the cutting speed; at the movement of the tool towards the contact with a rear edge one observes increase in the forces action $\Phi=\left\{\Phi_{1}, \Phi_{2}, \Phi_{3}\right\}^{T}$ depending on the speed. Fig. 1 "b" shows the approximation sections in bold lines. The forces $\Phi$ are presented in the form

$$
\left\{\begin{array}{c}
\Phi_{1}=\rho\left\{\int_{t-T}^{t}\left[V_{0,2}-d X_{2} / d t\right] d t\right\} \exp \alpha_{w}\left(-d X_{1} / d t\right) \\
\Phi_{2}=\rho\left[t_{P}^{(0)}-X_{1}(t)\right] \exp \left[\alpha_{w}\left(V_{0,2}-d X_{2} / d t\right)\right] \\
\Phi_{3}=k_{T}\left[\Phi_{1}+\Phi_{2}\right]
\end{array}\right.
$$

where $\rho$ - specific force reduced to the contact length $\left[\kappa_{2} /{ }_{M M}\right] ; \alpha_{w}$ - ratio of the force increase steepness. Take into account the forces delay $F$ modified with the parameter $T_{P}\left(S, V_{0,3}\right)$ depending on the area of the cut layer $S$ and the cutting rate $[6,7,9]$. Limit the consideration to the case when the forces projections on the directions $X_{1}, X_{2}, X_{3}$ are defined by slope ratios $\chi_{1}, \chi_{2}, \chi_{3}$. Along with this, $\left(\chi_{1}\right)^{2}+\left(\chi_{2}\right)^{2}+\left(\chi_{3}\right)^{2}=1$. Then

$$
F(t)=\left\{F_{1}, F_{2}, F_{3}\right\}^{T}=F_{0}(t)\left\{\chi_{1}, \chi_{2}, \chi_{3}\right\}^{T}
$$


where $F_{0}(t)=\left\{\left(F_{1}\right)^{2}+\left(F_{2}\right)^{2}+\left(F_{3}\right)^{2}\right\}^{0,5}$.

In contrast to the well-known research take into account the dependence of $T_{P}\left(S, V_{0,3}\right)$ on elastic deformations and industrial modes, i.e.

$$
\begin{aligned}
& T_{P}\left(S, V_{0,3}\right) d F_{i} / d t+F_{i}= \\
& =\rho_{0} \chi_{i}\left\{1+\mu \exp \left[-\alpha_{v}\left(V_{0,3}-d X_{3} / d t\right)\right]\right\}\left[t_{P}^{(0)}-X_{1}(t)\right] \int_{t-T}^{t}\left\{V_{0,2}-d X_{2} / d t\right\} d t, i=1,2,3
\end{aligned}
$$

where $T_{P}\left(S, V_{0,3}\right)$-cutting time constant in $[c] ; \rho_{0}$ - pressure on the tool front surface in $\left[\mathrm{kg} / \mathrm{mm}^{2}\right] ; \mu$ - nondimensional ratio; $\alpha_{v}$ - ratio defining the decrease in forces at speed rise in $[\mathrm{sek} / \mathrm{mm}] ; T=1 / \Omega_{0}=$ const - time of the part rotation. In (7) the time constant

$$
T_{P}\left(S, V_{0,3}\right)=\frac{\kappa S_{p}(t) t_{p}(t)}{V_{0,3}(t)},
$$

where $S_{p}(t)=\int_{t-T}^{t}\left\{V_{2}^{(0)}-d X_{2} / d t\right\} d t ; t_{p}(t)=t_{p}^{(0)}-X_{1}(t) ; \kappa$ - dimension ratio $M M^{-1}$; $V_{3}(t)=V_{0,3}-d X_{3} / d t$. Analyze the system with constant modes, i.e. $S_{p}^{(0)}=\int_{t-T}^{t}\left\{V_{0,3}\right\} d t=$ const,$t_{p}^{(0)}=$ const and $V_{0,3}=$ const. The systems (1) - (7) characterize a full mathematical model of the evolutionary dynamic system.

\section{Stability of the evolutionary trajectory}

Evolutionary processes at cutting are quite slow. That is why introduce a stationary evolutionary trajectory $X^{(\ni)}=\left\{X_{1}^{(\ni)}, X_{2}^{(Э)}, X_{3}^{(\ni)}\right\}^{T}$ in the consideration which corresponds to the trajectories of forces $F^{(\ni)}(t)=\left\{F_{1}^{(\ni)}, F_{2}^{(\ni)}, F_{3}^{(\ni)}\right\}^{T}$ and $\Phi^{(\ni)}(t)=\left\{\Phi_{1}^{(\ni)}, \Phi_{2}^{(Э)}, \Phi_{3}^{(Э)}\right\}^{T}$ in a single system, as well the trajectories of parameters (2). If the trajectory $X^{(\ni)}$ along the entire duration of the system functioning is asymptotically stable, it characterizes the attracting set, i.e, the attractor of the tool deformation displacements in the course of evolution. To define it, one can use the following system

$$
\begin{aligned}
& c_{\Sigma} X^{(\ni)}=F_{\Sigma}^{(\ni)}, \\
& \text { where } c_{\Sigma}=\left[\begin{array}{ccc}
c_{1,1}+\rho_{0} \chi_{1}\left[1+\mu \exp \left(-\alpha_{v} V_{3,0}\right)\right] S_{P}^{(0)} ; & c_{2,1} ; & c_{3,1} \\
c_{1,2}+\rho_{0} \chi_{2}\left[1+\mu \exp \left(-\alpha_{v} V_{3,0}\right)\right] S_{P}^{(0)}+\rho \exp \left(\alpha_{w} V_{2,0}\right) ; & c_{2,2} ; & c_{3,2} \\
c_{1,3}+\rho_{0} \chi_{3}\left[1+\mu \exp \left(-\alpha_{v} V_{3,0}\right)\right] S_{P}^{(0)}+\rho k_{T} \exp \left(\alpha_{w} V_{2,0}\right) ; & c_{2,3} ; & c_{3,3}
\end{array}\right] \text {; } \\
& F_{\Sigma}^{(\ni)}=F^{(\ni)}+\Phi^{(Э)} \text {; }
\end{aligned}
$$




$$
F^{(\ni)}=\left[\begin{array}{c}
\rho_{0} \chi_{1}\left[1+\mu \exp \left(-\alpha_{v} V_{3,0}\right)\right] S_{P}^{(0)} t_{P}^{(0)} \\
\rho_{0} \chi_{2}\left[1+\mu \exp \left(-\alpha_{v} V_{3,0}\right)\right] S_{P}^{(0)} t_{P}^{(0)}+\rho \exp \left(\alpha_{w} V_{2,0}\right) t_{P}^{(0)} \\
\rho_{0} \chi_{3}\left[1+\mu \exp \left(-\alpha_{v} V_{3,0}\right)\right] S_{P}^{(0)} t_{P}^{(0)}+\rho k_{T}\left[t_{P}^{(0)} \exp \left(\alpha_{w} V_{2,0}\right)+S_{P}^{(0)}\right]
\end{array}\right]=\left[\begin{array}{c}
F_{1}^{(\ni)} \\
F_{2}^{(\ni)} \\
F_{3}^{(\ni)}
\end{array}\right]
$$

This system should be complemented with integral operators (3) and the equation (2). Then for defining $X^{(\ni)}, F_{\Sigma}^{(\ni)}$ and the parametric trajectories it is necessary to solve the integral equation. However, its solving virtually always leads to the necessity of numerical integration. That is why it seems simpler to use the application software package Matlab Simulink. In this case the simulation of the integral operator (3) can be conducted on the basis of the approximating the core with its constant values at increments $\Delta t=$ const. Along with this, $T_{\Sigma}=n \Delta t$. Here $T_{\Sigma}$ - time during which the core function attenuates by $98 \%$. Then, the following is correct

$$
\begin{aligned}
& \phi_{i}(t)=c_{\phi}\left\{N(t)+c_{\phi}^{*} \int_{0}^{t} W(t-\varsigma) N(\varsigma) d \varsigma v_{w}(t) \approx c_{\phi}\left\{N(t)+c_{\phi}^{*} \sum_{i=0}^{i=n} W_{i} \int_{i \Delta t}^{(i+1) \Delta t} N(\xi) d \xi\right\}\right. \\
& W_{i}=0,5\{W[t-(i+1) \Delta t]+W[t-i \Delta t]\} .
\end{aligned}
$$

All $W_{i}=0$ at $[t-i \Delta t]<0$. Note that $T_{\Sigma}$ is several orders greater than the one during the evolutionary parameter change. This calculation pattern is congruent with the software product Matlab Simulink as $N(t-i \Delta t)$ is easily simulated on the basis of the dead time elements. Evolutionary trajectories are defined by initial parameters and industrial modes at the condition the trajectory is asymptotically stable. In case the trajectory loses its stability a cascade of bifurcations occurs in the system attracting a set of strain displacements and influencing the system evolution. In this case it is necessary to analyze the dynamic system in general while the evolution becomes difficult to predict. To obtain the stability of the point $X^{(\ni)}$, it is necessary to know the linearized equation in variations. After replacement of $X_{i}=X_{i}^{(\ni)}+x_{i}, F_{i}=F_{i}^{(\ni)}+f, i=1,2,3$ obtain

$$
A \frac{d^{2} X_{\Sigma}}{d t^{2}}+B \frac{d X_{\Sigma}}{d t}+C X_{\Sigma}=0,
$$

where $A=\left[\begin{array}{cccc}m & 0 & 0 & 0 \\ 0 & m & 0 & 0 \\ 0 & 0 & m & 0 \\ 0 & 0 & 0 & 0\end{array}\right]$ 


$$
\begin{aligned}
& B= \\
& =\left[\begin{array}{cccccc}
h_{1,1}+\rho \alpha_{w} S_{P}^{(0)} & h_{2,1} & h_{3,1} & 0 & 0 & 0 \\
h_{1,2} & h_{2,2}+\rho \alpha_{w}\left(t_{P}^{(0)}-X_{1}^{*}\right) & h_{3,2} & 0 & 0 & 0 \\
h_{1,3}+\rho \alpha_{w} k_{T} S_{P}^{(0)} & h_{2,3}+\rho \alpha_{w} k_{T}\left(t_{P}^{(0)}-X_{1}^{*}\right) & h_{3,3} & 0 & 0 & 0 \\
0 & 0 & \chi_{1} \rho_{0} \mu\left(t_{P}^{(0)}-X_{1}^{*}\right) S_{P}^{(0)} e^{-\alpha_{v} V_{0,3}} & -\frac{\chi_{1}\left(t_{P}^{(0)}-X_{1}^{*}\right) S_{P}^{(0)}}{V_{0,3}} & 0 & 0 \\
0 & 0 & \chi_{2} \rho_{0} \mu\left(t_{P}^{(0)}-X_{1}^{*}\right) S_{P}^{(0)} e^{-\alpha_{v} V_{0,3}} & 0 & -\frac{\chi_{2}\left(t_{P}^{(0)}-X_{1}^{*}\right) S_{P}^{(0)}}{V_{0,3}} & 0 \\
0 & 0 & \chi_{3} \rho_{0} \mu\left(t_{P}^{(0)}-X_{1}^{*}\right) S_{P}^{(0)} e^{-\alpha_{v} V_{0,3}} & 0 & 0 & -\frac{\chi_{3}\left(t_{P}^{(0)}-X_{1}^{*}\right) S_{P}^{(0)}}{V_{0,3}}
\end{array}\right] \\
& C=\left[\begin{array}{cccccc}
c_{1,1} & c_{2,1}+\rho & c_{3,1} & -\chi_{1} & 0 & 0 \\
c_{1,2}+\rho e^{-\alpha_{w} V_{0,2}} & c_{2,2} & c_{3,2} & 0 & -\chi_{2} & 0 \\
c_{1,3}+\rho k_{T} e^{-\alpha_{w} V_{0,2}} & c_{2,3}+\rho k_{T} & c_{3,3} & 0 & 0 & -\chi_{3} \\
-\chi_{1} \rho_{0} S_{P}^{(0)}\left(1+\mu e^{-\alpha_{v} V_{0,3}}\right) & -\chi_{1} \rho_{0}\left(t_{P}^{(0)}-X_{1}^{*}\right)\left(1+\mu e^{-\alpha_{v} V_{0,3}}\right) & 0 & -\chi_{1} & 0 & 0 \\
-\chi_{2} \rho_{0} S_{P}^{(0)}\left(1+\mu e^{-\alpha_{v} V_{0,3}}\right) & -\chi_{2} \rho_{0}\left(t_{P}^{(0)}-X_{1}^{*}\right)\left(1+\mu e^{-\alpha_{v} V_{0,3}}\right) & 0 & 0 & --\chi_{2} & 0 \\
-\chi_{3} \rho_{0} S_{P}^{(0)}\left(1+\mu e^{-\alpha_{v} V_{0,3}}\right) & -\chi_{3} \rho_{0}\left(t_{P}^{(0)}-X_{1}^{*}\right)\left(1+\mu e^{-\alpha_{v} V_{0,3}}\right) & 0 & 0 & 0 & --\chi_{3}
\end{array}\right]
\end{aligned}
$$

The system (10) allows identifying the areas of asymptotic trajectory stability $X^{(\ni)}$ in the space of evolutionary parameters at all stages of evolution.

\section{Examples of evolutionary changes in deformation displacements}

Consider the example of the evolutionary trajectory of strain displacements of the tool at axial turning. Table 1 provides the parameters of the tool subsystem $\left(m=4 \cdot 10^{-3} \mathrm{~kg} \cdot \mathrm{s}^{2} / \mathrm{mm}\right)$ and Table 2 - initial values $p_{0, i}, i=1,2,3,4$ as well as constant parameter values. Table 3 gives the parameters of integral operators. Without going into details, analyze the examples of evolutionary trajectories (Fig.2). Here the controlling parameter is cutting depth of $t_{P}=0,5 \mathrm{~mm}$ and $t_{P}=1,5 \mathrm{~mm}$. The depth of cut for one rotation $S_{P}^{(0)}=0,1 \mathrm{~mm} /$ turnover and cutting speed $V_{0,3}=2,0 \mathrm{~m} / \mathrm{sek}$.

Table 1. Values of the viscosity coefficient matrix

\begin{tabular}{|c|c|c|c|c|c|}
\hline $\begin{array}{l}h_{1,1}, \\
\mathrm{~kg} \cdot \mathrm{sek} / \mathrm{mm}\end{array}$ & $\begin{array}{l}h_{2,2}, \\
\mathrm{~kg} \cdot \mathrm{sek} / \mathrm{mm}\end{array}$ & $\begin{array}{l}h_{3,3}, \\
\mathrm{~kg} \cdot \mathrm{sek} / \mathrm{mm}\end{array}$ & $\begin{array}{l}h_{1,2}=h_{2,1}, \\
\mathrm{~kg} \cdot \mathrm{sek} / \mathrm{mm}\end{array}$ & $\begin{array}{l}h_{1,3}=h_{3,1}, \\
\mathrm{~kg} \cdot \mathrm{sek} / \mathrm{mm}\end{array}$ & $\begin{array}{l}h_{2,3}=h_{3,2}, \\
\mathrm{~kg} \cdot \mathrm{sek} / \mathrm{mm}\end{array}$ \\
\hline 0,25 & 0,15 & 0,15 & 0,1 & 0,08 & 0,08 \\
\hline$c_{1,1}$, & $c_{2,2}$, & $c_{3,3}$, & $c_{1,2}=c_{2,1}$, & $c_{1,3}=c_{3,1}$, & $\mathrm{c}_{2,3}=c_{3,2}$, \\
$\mathrm{kg} / \mathrm{mm}$ & $\mathrm{kg} / \mathrm{mm}$ & $\mathrm{kg} / \mathrm{mm}$ & $\mathrm{kg} / \mathrm{mm}$ & $\mathrm{kg} / \mathrm{mm}$ & $\mathrm{kg} / \mathrm{mm}$ \\
\hline 1000 & 800 & 800 & 200 & 100 & 100 \\
\hline
\end{tabular}

Table 2. The values of the coefficients in the expressions describing the forces

\begin{tabular}{|c|c|c|c|c|c|}
\hline$\rho_{0}, \mathrm{~kg} / \mathrm{mm}^{2}$ & $\alpha_{w}, \mathrm{sek} / \mathrm{mm}$ & $\alpha_{v}, \mathrm{sek} / \mathrm{mm}$ & $\mu$ & $k, \mathrm{~mm}^{-1}$ & $\rho, \mathrm{kg} / \mathrm{mm}$ \\
\hline 300,0 & 20 & 0,2 & 0,5 & 1,2 & 0,5 \\
\hline
\end{tabular}


Table 3. Values of stiffness matrix coefficients

\begin{tabular}{|c|c|c|c|c|}
\hline$c_{\varphi}^{\left(\rho_{0}\right)}, 1 / \mathrm{mm}^{3}$ & $c_{\varphi}^{(\rho)}, 1 / \mathrm{mm}^{2}$ & $c_{\varphi}^{\left(\alpha_{w}\right)}$, sek $/ \mathrm{kg}(\mathrm{mm})^{2}$ & $c_{\varphi}^{*},(c)^{-1}$ & $c_{\varphi}^{(k)},(\mathrm{mm} \cdot \mathrm{c})^{-2}$ \\
\hline $0,4 \cdot 10^{-3}$ & $0,12 \cdot 10^{-3}$ & $3 \cdot 10^{-4}$ & 0,1 & $4 \cdot 10^{-6}$ \\
\hline
\end{tabular}

At the cutting depth $t_{P}=0,5 \mathrm{~mm}$ the evolutionary trajectory is asymptotically stable during the whole period of cutting forces operation (Fig.2). At the depth $t_{P}=1,5 \mathrm{~mm}$ mainly by means of the parametric evolution the system, starting from point A, loses its stability and various processes occur in this system causing multiple strain displacements. At this, there are sections "B-C" and "D-E" where chaotic oscillations occur.
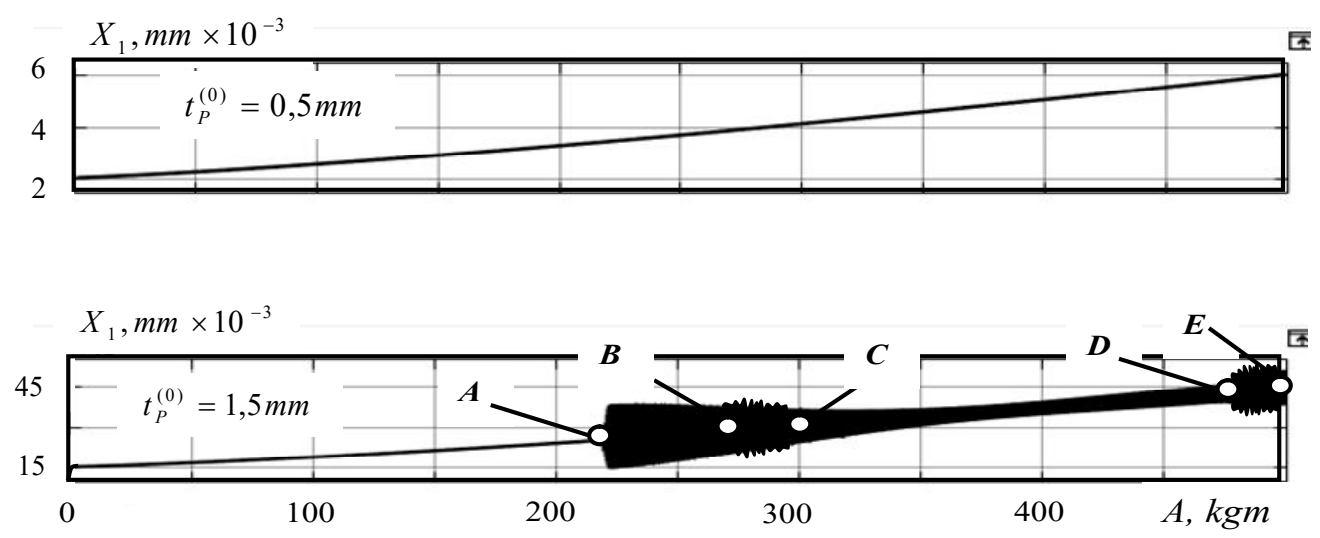

Fig. 2. The example of changing the trajectories of strain displacements in the course of work of cutting force in time.

\section{Conclusion}

The dynamic cutting system in the course of functioning changes its properties due to the cutting forces action. These changes manifest in the variations of the parameters of dynamic connection formed by the machining process. As a result elastic deformation properties of the tool change. The proposed mathematical description allows predicting the evolutionary trajectory of tool strain displacements in relation to the workpiece which leads to the changes in the diameter of the machined part. For practical purposes it is necessary not only to predict the evolutionary trajectory but also to analyze its stability. To analyze the stability, one can use the dependencies provided in the article. Predicting the evolutionary trajectory and providing its asymptotic stability leads to outlining the new ways of the improvement of the machine treatment due to the coordination of the external control (for example, from the NC system) with the system evolutionary properties. Here we are talking, in particular, about the energy efficiency of the entire processing process.

The study was performed under financial support of Russian Foundation for basic research grant 19-08-00022.

\section{References}

1. G. Haken, Tajny prirody. Sinergetika: uchenie o vzaimodejstvii (Institut komp'yuternyh issledovanij, Moscow-Izhevsk, 2003) 
2. I. Prigozhin, Ot sushchestvuyushchego k voznikayushchemu (Nauka, Moscow, 1985).

3. I. Prigozhin, I. Stengers, Poryadok iz haosa: Novyj dialog cheloveka s prirodoj (Progress, Moscow, 1986)

4. A. A. Kolesnikov, Prikladnaya sinergetika: osnovy sistemnogo sinteza (TTI YUFU, Taganrog, 2007)

5. A. A. Kolesnikov, Sinergetika i problemy teorii upravleniya (Fizmatlit, Moscow, 2004)

6. V.L. Zakovorotnyj, M.B. Flek, Dinamika processa rezaniya. Sinergeticheskij podhod. (Terra, Rostov-na-Donu, 2006)

7. V.L. Zakovorotnyj, A.D. Luk'yanov, Nguen Dong An', Fam Din' Tung, Sinergeticheskij sistemnyj sintez upravlyaemoj dinamiki metallorezhushchih stankovs uchetom evolyucii svyazej (DGTU, Rostov-na-Donu, 2008)

8. R.S. Hahn, Trans. of ASME, B, 76, 356 (1954)

9. V.A. Kudinov, Dinamika stankov (Mashinostroenie, Moscow, 1967)

10. J. Tlusty, F. Ismail, Ann. CIRP, 30, 1, 299 (1981)

11. I. Tlusty, Self-oscillations in machine tools. Trans. with the Czech. Mashgiz, Moscow, 1956)

12. S.A. Tobias, Machine Tool Vibrations (Blackie, London, 1965)

13. V.L. Vejc, D.V. Vasil'kov, STIN, 6, 9 (1999)

14. S.A. Voronov, A.V. Nepochatov, I.A. Kiselev, Izvestiya vysshih uchebnyh zavedenij. Mashinostroenie, 1, 50 (2011)

15. V. L. Zakovorotny, V. P. Lapshin, T. S. Babenko, Procedia Engineering, 206, 68 (2017)

16. YU.I. Gorodeckij, Vestnik Nizhegorodskogo universiteta im. N.I. Lobachevskogo. Seriya: Matematicheskoe modelirovanie i optimal'noe upravlenie, 2, 69 (2001)

17. B. Balachandran, Phil. Trans. Roy. Soc. London A: Math. Phys. Engin. Sci., 359, 1781, 793 (2001)

18. G. Litak, Chaos Solit. Fract., 13, 7, 1531 (2002)

19. G. Litak, R. Rusinek, Mechanic, 47, 6, 1517 (2012)

20. N. S. Namachchivaya, R. Beddini, J. Nonlin. Sci., 13, 3, 265 (2003)

21. P. Wahi, A. Chatterjee, J. Non-Lin. Mech., 43, 2, 111 (2008)

22. J. Warminski, G. Litak, J. Lipski, M. Wiercigroch, M. P. Cartmell, IUTAM/IFToMMSymp. Synthesis of Nonlinear Dynamical Systems, 73, 275 (2000)

23. G. Stepan, R. Szalai, T. Insperger, Nonlinear dynamics of high-speed milling subjected to regenerative effect. Nonlinear Dynamics of Production Systems (Wiley-VCH, Weinheim, 2004)

24. G. Stepan, Phil. Trans. Roy. Soc. London: A Math. Phys. Engin. Sci., 359, 1781, 739 (2001)

25. A. M. Gouskov, S. A. Voronov, H. Paris, S. A. Batzer, Commun. Nonlin. Sci. Numer. Simul., 7, 4, 207 (2002)

26. S.A. Voronov, I.A. Kiselev, Mashinostroenie i inzhenernoe obrazovanie, 2 (51), 9 (2017)

27. S.A. Vasin, L.A. Vasin, Naukoemkie tekhnologii v mashinostroenii, 1, 11 (2012) 
28. R. Rusinek, M. Wiercigroch, P. Wahi, International Journal of Bifurcation and Chaos, 24, 9, 1450115 (2014)

29. R. Rusinek, M. Wiercigroch, P. Wahi, Int. J. Mech. Sci., 89, 167 (2014)

30. V.L. Zakovorotny, A.D. Lukyanov, International Journal of Mechanical Engineering and Automation, 1, 5, 271 (2014)

31. V.L. Zakovorotny, V.P. Lapshin, T.S. Babenko, Russian Engineering Research, 38 (9), 707 (2018)

32. V. L. Zakovorotny, V. E. Gvindzhiliya, Russian Engineering Research, 39, 5, 423 (2019)

33. A.D. Myshkis, Matematika. Special'nye kursy (Nauka, Moscow,1971) 